\title{
Microelectrophoretic investigation of the interactions between liposomal membranes formed from a phosphatidylcholine- phosphatidylglycerol mixture and monovalent ions
}

\author{
Joanna Kotyńska ${ }^{1, a}$ and Zbigniew A. Figaszewski ${ }^{1,2}$ \\ 1 Institute of Chemistry, University of Bialystok, Al. Pilsudskiego 11/4, 15-443 Bialystok, Poland \\ 2 Laboratory of Electrochemical Power Sources, Faculty of Chemistry, University of Warsaw, Pasteur St. 1, 02-093 Warsaw, \\ Poland
}

Received 22 July 2014 and Received in final form 17 September 2014

Published online: 20 October 2014

(C) The Author(s) 2014. This article is published with open access at Springerlink.com

\begin{abstract}
In this paper, we characterized the interactions between two-component liposomal membranes and monovalent electrolyte ions. Liposomes were formed from neutral (phosphatidylcholine) and anionic (phosphatidylglycerol) lipids mixed in various ratios. Microelectrophoresis was used to determine the dependence of the membrane surface charge density on the $p \mathrm{H}$ of the electrolyte solution. Changes in the membrane electric charge caused by the adsorption of $\mathrm{Na}^{+}, \mathrm{Cl}^{-}, \mathrm{H}^{+}$, and $\mathrm{OH}^{-}$ions were observed, and the equilibria among these ions and the phosphatidylcholine-phosphatidylglycerol membrane surface were quantified. We proposed a mathematical model for characterizing these equilibria. Using this model, together with experimental data of the membrane surface charge density, we determined association constants characterizing the equilibria. Knowledge of these parameters was necessary to calculate the theoretical curves of the model. We validated the model by curve-fitting the experimental data points to simulated data generated by the model.
\end{abstract}

\section{Introduction}

Many researchers are interested in the adsorption of ions in solution onto the lipid membranes [1-7], as this process not only induces physicochemical and electrical changes in the membrane (e.g., in its surface charge), but also plays an important role in its overall functional behavior (e.g., membrane fusion and transport). Ion adsorption on the lipid membrane surface has been explored through various techniques, including nuclear magnetic resonance $[8$, 9], Langmuir method [10-12] microelectrophoresis [13-15] and computational methods, such as molecular dynamics simulations $[16,17]$. In particular, microelectrophoresis can be used to determine membranes surface charge density values.

The membrane surface charge density is an important parameter for characterizing equilibria in natural or artificial membranes. Measured membrane surface charge density values strongly depend on several factors, including the $p \mathrm{H}$ and ionic strength of the electrolyte, as well as the lipid composition of the membrane [18]. The incorporation of compounds with a negative charge (e.g., phosphatidylglycerol [PG]) or a positive charge (e.g., decylamine) within a membrane bilayer formed of neutral

a e-mail: joannak@uwb.edu.pl lipids (e.g., phosphatidylcholine [PC]) will alter the total membrane surface charge. However, the membrane surface charge is seldom studied or used in studies of membraneenvironment interactions. Moreover, there is a noticeable lack of published studies regarding the equilibria between charged groups of membrane compounds and surrounding ions.

$\mathrm{PC}$ is the most widespread and dominant of the membrane phospholipids [19]. It forms stable liposomal membranes, and its properties are easily modified by the addition of other amphiphilic molecules. Whereas PG is the major anionic lipid component of higher plant and bacterial membranes [20], animal cells contain little PG (e.g., only $2 \%$ of the membrane phospholipid volume in animal blood cells is PG) [21]. PG molecules in bacterial membranes play a similar role as cholesterol does in animal membranes. Specifically, bacterial PG regulates membrane permeability, lipid packing, and the ordering of phospholipid acyl chains [22].

In this paper, we analyzed the effect of the membrane lipid composition on its surface charge, using PCbased membranes that were modified by PG. We studied the influence of electrolyte ion adsorption on the electric charge of the PC-PG liposome surface over the $p \mathrm{H}$ range of 2 to 10.5 , and we determined the membrane 
surface charge density by microelectrophoresis. We previously developed a mathematical model to simulate and characterize interactions between solution ions (e.g., $\mathrm{Na}^{+}$, $\left.\mathrm{Cl}^{-}, \mathrm{H}^{+}, \mathrm{OH}^{-}\right)$and the membrane surface [23]. We determined the association constants of the $-\mathrm{PO}^{(-)}$and $-\mathrm{N}^{(+)}\left(\mathrm{CH}_{3}\right)_{3}$ groups of $\mathrm{PC}$ with the $\mathrm{H}^{+}, \mathrm{OH}^{-}, \mathrm{Na}^{+}$, and $\mathrm{Cl}^{-}$ions $\left(K_{\mathrm{A}_{1} \mathrm{H}}, K_{\mathrm{B}_{1} \mathrm{OH}}, K_{\mathrm{A}_{1} \mathrm{Na}}, K_{\mathrm{B}_{1} \mathrm{Cl}}\right)$. Here, we provide a quantitative description of the equilibria between twocomponent liposomal membranes and monovalent ions. We used these values to calculate association constants of the $-\mathrm{PO}^{(-)}$group of $\mathrm{PG}$ with $\mathrm{H}^{+}$and $\mathrm{Na}^{+}$ions $\left(K_{\mathrm{A}_{2} \mathrm{H}}, K_{\mathrm{A}_{2} \mathrm{Na}}\right)$, thereby providing an experimental verification for the proposed model.

Data presented in this work, obtained in result of mathematical derivation and confirmed experimentally, are of great importance for interpretation of phenomena occurring in lipid membranes. A quantitative description of equilibria between lipid membranes and solution ions lets us understand the processes that take place on membrane surface. The equilibria are particularly significant from the standpoint of cell functioning. Ion-membrane interactions modulate a range of physicochemical and electrical properties of membranes and they are important in the course of the multiple processes involving membranes in the living cell (e.g.,transport mechanism). Solution of even the smallest problem of biological membranes, enriches knowledge of their properties and functioning, thereby moving us to a better understanding of many processes in a human organism.

\section{Experimental}

\subsection{Materials}

L- $\alpha$-Phosphatidylcholine (PC) from egg yolk and L$\alpha$-Phosphatidyl-DL-glycerol (PG) were purchased from Sigma-Aldrich. HPLC grade chloroform was purchased also from Sigma-Aldrich. All solutions and cleaning procedures were performed with water purified using a Milli-Qll system (18.2, Millipore, USA).

\subsection{Preparation of liposomes}

Liposomes were prepared by a sonication method. Dry lipids (neutral PC and negatively charged PG) were weighed, dissolved in chloroform $\left(10 \mathrm{mg} \mathrm{ml}^{-1}\right)$, and mixed in various molar ratios of PC:PG (40:1, 20:1, 10:1). The solvent was evaporated under a gentle stream of argon to obtain dry lipid film. Then, the film was hydrated with $0.9 \% \mathrm{NaCl}$. Liposomes were formed by sonicating the suspension using an ultrasound generator UD 20 (Techpan, Poland). Sonication was applied five times for 90 seconds. Since during the process heat is liberated, cooling the suspension is necessary. It was carried out by using an ice bath (container with a mixture of ice and dry sodium chloride).

\subsection{Microelectrophoretic mobility measurements}

The electrophoretic mobility of liposomes was measured using Zetasizer Nano ZS (Malvern Instruments, UK) apparatus. The measurements were carried out as a function of $p \mathrm{H}$. The liposomes were suspended in $\mathrm{NaCl}$ solution and titrated to the desired $p \mathrm{H}$ using $\mathrm{HCl}$ or $\mathrm{NaOH}$. The reported values represent the average of at least six measurements performed at a given $p \mathrm{H}$.

From electrophoretic mobility measurements the surface charge density was determined using the equation [24]

$$
\delta=\frac{\eta \cdot u}{d}
$$

where $\eta$ is the viscosity of solution, $u$ the electrophoretic mobility, $d$ the diffuse layer thickness.

The diffuse layer thickness was determined from the formula [25]

$$
d=\sqrt{\frac{\varepsilon \cdot \varepsilon_{0} \cdot R \cdot T}{2 \cdot F^{2} \cdot I}},
$$

where $R$ is the gas constant, $T$ is the temperature, $F$ is the Faraday number and $I$ is the ionic strength of $0.9 \%$ $\mathrm{NaCl}, \varepsilon \varepsilon_{0}$ the permeability of the electric medium.

\section{Theory}

The adsorption of monovalent ions on a membrane surface has been mathematically characterized. A six-equilibrium model has been used to describe the dependence of the surface charge density of liposomal membranes formed from a PC-PG mixture on the $p \mathrm{H}$ of the electrolyte solution. This model assumes the existence of six equilibria. Four of these equilibria are associated with negative groups $\left(-\mathrm{PO}^{(-)}\right.$ of $\mathrm{PC}$ and $-\mathrm{PO}^{(-)}$of $\mathrm{PG}$ ) and with $\mathrm{H}^{+}$and $\mathrm{Na}^{+}$ions. The other two equilibria are associated with positive PC species, as well as $\mathrm{OH}^{-}$and $\mathrm{Cl}^{-}$ions. Previously, we developed a mathematical formulation of this six-equilibrium model, which we used to simulate the functional behavior of the phosphatidylserine membrane-monovalent ion system [23] and to determine theoretical membrane surface charge densities.

The $\mathrm{H}^{+}, \mathrm{OH}^{-}, \mathrm{Na}^{+}$, and $\mathrm{Cl}^{-}$ions are adsorbed at the $\mathrm{PC}: \mathrm{PG}$ membrane surface, and the adsorption equilibria can be presented in the following way:

$$
\begin{aligned}
& \mathrm{A}_{1}^{-}+\mathrm{H}^{+} \rightleftarrows \mathrm{A}_{1} \mathrm{H}, \\
& \mathrm{A}_{2}^{-}+\mathrm{H}^{+} \rightleftarrows \mathrm{A}_{2} \mathrm{H}, \\
& \mathrm{B}_{1}^{+}+\mathrm{OH}^{-} \rightleftarrows \mathrm{B}_{1} \mathrm{OH}, \\
& \mathrm{A}_{1}^{-}+\mathrm{Na}^{+} \rightleftarrows \mathrm{A}_{1} \mathrm{Na}, \\
& \mathrm{A}_{2}^{-}+\mathrm{Na}^{+} \rightleftarrows \mathrm{A}_{2} \mathrm{Na}, \\
& \mathrm{B}_{1}^{+}+\mathrm{Cl}^{-} \rightleftarrows \mathrm{B}_{1} \mathrm{Cl},
\end{aligned}
$$

where $\mathrm{A}_{1}^{-}$is group $-\mathrm{PO}^{(-)}, \mathrm{B}_{1}^{+}$is group $-\mathrm{N}^{(+)}\left(\mathrm{CH}_{3}\right)_{3}$, of phosphatidylcholine and $\mathrm{A}_{2}^{-}$is group $-\mathrm{PO}^{(-)}$of phosphatidylglycerol. 
The association constants are expressed in the following manner:

$$
\begin{aligned}
K_{\mathrm{A}_{1} \mathrm{H}} & =\frac{a_{\mathrm{A}_{1} \mathrm{H}}}{a_{\mathrm{A}_{1}^{-}} a_{\mathrm{H}^{+}}}, \\
K_{\mathrm{A}_{2} \mathrm{H}} & =\frac{a_{\mathrm{A}_{2} \mathrm{H}}}{a_{\mathrm{A}_{2}^{-}} a_{\mathrm{H}^{+}}}, \\
K_{\mathrm{B}_{1} \mathrm{OH}} & =\frac{a_{\mathrm{B}_{1} \mathrm{OH}}}{a_{\mathrm{B}_{1}^{+}} a_{\mathrm{OH}^{-}}}, \\
K_{\mathrm{A}_{1} \mathrm{Na}} & =\frac{a_{\mathrm{A}_{1} \mathrm{Na}}}{a_{\mathrm{A}_{1}^{-}} a_{\mathrm{Na}^{+}}}, \\
K_{\mathrm{A}_{2} \mathrm{Na}} & =\frac{a_{\mathrm{A}_{2} \mathrm{Na}}}{a_{\mathrm{A}_{2}^{-}} a_{\mathrm{Na}^{+}}}, \\
K_{\mathrm{B}_{1} \mathrm{Cl}} & =\frac{a_{\mathrm{B}_{1} \mathrm{Cl}}}{a_{\mathrm{B}_{1}^{+} a_{\mathrm{Cl}}}},
\end{aligned}
$$

where $K_{\mathrm{A}_{1} \mathrm{H}}, K_{\mathrm{A}_{2} \mathrm{H}}, K_{\mathrm{A}_{1} \mathrm{Na}}, K_{\mathrm{A}_{2} \mathrm{Na}}, K_{\mathrm{B}_{1} \mathrm{OH}}, K_{\mathrm{B}_{1} \mathrm{Cl}}$ are association constants; $a_{\mathrm{A}_{1}^{-}}, a_{\mathrm{A}_{1} \mathrm{H}}, a_{\mathrm{A}_{1} \mathrm{Na}}, a_{\mathrm{A}_{2}^{-}}, a_{\mathrm{A}_{2} \mathrm{H}}, a_{\mathrm{A}_{2} \mathrm{Na}}$, $a_{\mathrm{B}_{1}^{+}}, a_{\mathrm{B}_{1} \mathrm{OH}}, a_{\mathrm{B}_{1} \mathrm{Cl}}$ are surface concentrations of particular groups on the membrane surface $\left[\mathrm{mol} \mathrm{m}^{-2}\right], a_{\mathrm{H}^{+}}, a_{\mathrm{Na}^{+}}$, $a_{\mathrm{OH}^{-}}, a_{\mathrm{Cl}^{-}}$are the volumetric concentrations of the solution ions $\left[\mathrm{mol} \mathrm{m}^{-3}\right]$.

Surface concentrations of $\mathrm{PC}$ and $\mathrm{PG}$ are given by $C_{\mathrm{PC}}$ and $C_{\mathrm{PG}}$ :

$$
\begin{aligned}
& a_{\mathrm{A}_{1}^{-}}+a_{\mathrm{A}_{1} \mathrm{H}}+a_{\mathrm{A}_{1} \mathrm{Na}}=C_{\mathrm{PC}}, \\
& a_{\mathrm{B}_{1}^{+}}+a_{\mathrm{B}_{1} \mathrm{OH}}+a_{\mathrm{B}_{1} \mathrm{Cl}}=C_{\mathrm{PC}}, \\
& a_{\mathrm{A}_{2}^{-}}+a_{\mathrm{A}_{2} \mathrm{H}}+a_{\mathrm{A}_{2} \mathrm{Na}}=C_{\mathrm{PG}} .
\end{aligned}
$$

The surface charge density of PC-PG membrane is given by the equation

$$
\delta=\left(a_{\mathrm{B}_{1}^{+}}-a_{\mathrm{A}_{1}^{-}}-a_{\mathrm{A}_{2}^{-}}\right) F .
$$

Equations (9)-(18) are treated as a system of equations. Elimination of the: $a_{\mathrm{A}_{1}^{-}}, a_{\mathrm{A}_{1} \mathrm{H}}, a_{\mathrm{A}_{1} \mathrm{Na}}, a_{\mathrm{A}_{2}^{-}}, a_{\mathrm{A}_{2} \mathrm{H}}, a_{\mathrm{A}_{2} \mathrm{Na}}$, $a_{\mathrm{B}_{1}^{+}}, a_{\mathrm{B}_{1} \mathrm{OH}}, a_{\mathrm{B}_{1} \mathrm{Cl}}$ parameters from the system of equations yields the following formula:

$$
\begin{aligned}
\frac{\delta}{F}= & \frac{C_{\mathrm{PC}}}{1+K_{\mathrm{B}_{1} \mathrm{OH}} a_{\mathrm{OH}^{-}}+K_{\mathrm{B}_{1} \mathrm{Cl}} a_{\mathrm{Cl}^{-}}} \\
& -\frac{C_{\mathrm{PC}}}{1+K_{\mathrm{A}_{1} \mathrm{H}} a_{\mathrm{H}^{+}}+K_{\mathrm{A}_{1} \mathrm{Na}} a_{\mathrm{Na}^{+}}} \\
& -\frac{C_{\mathrm{PG}}}{1+K_{\mathrm{A}_{2} \mathrm{H}} a_{\mathrm{H}^{+}}+K_{\mathrm{A}_{2} \mathrm{Na}} a_{\mathrm{Na}^{+}}} .
\end{aligned}
$$

In order to determine the association constants of particular ions with functional groups localized at the membrane surface, a simplification of the above equation to a linear form at high $\mathrm{H}^{+}\left(a_{\mathrm{H}^{+}} \rightarrow \infty\right)$ and low $\mathrm{H}^{+}\left(a_{\mathrm{H}^{+}} \rightarrow 0\right)$ concentrations is necessary. The mathematical operations resulting in two linear equations is presented in detail in our previous papers $[23,26]$. Applying the same procedure to eq. (19) resulted in eq. (20) (correct for high hydrogen ion concentrations) and eq. (21) (correct for low hydrogen ion concentrations):

$$
\begin{aligned}
& \frac{\delta a_{\mathrm{H}^{+}}}{F}=\frac{C_{\mathrm{PC}}}{1+K_{\mathrm{B}_{1} \mathrm{Cl}} a_{\mathrm{Cl}^{-}}} a_{\mathrm{H}^{+}} \\
& -\left[\frac{C_{\mathrm{PC}} K_{\mathrm{B}_{1} \mathrm{OH}} K_{w}}{\left(1+K_{\mathrm{B}_{1} \mathrm{Cl}} a_{\mathrm{Cl}^{-}}\right)^{2}}+\frac{C_{\mathrm{PG}}}{K_{\mathrm{A}_{2} \mathrm{H}}}+\frac{C_{\mathrm{PC}}}{K_{\mathrm{A}_{1} \mathrm{H}}}\right] \text {, } \\
& \frac{\delta}{F a_{H^{+}}}= \\
& -\left[\frac{C_{\mathrm{PG}}}{\left(1+K_{\mathrm{A}_{2} \mathrm{Na}} a_{\mathrm{Na}^{+}}\right)}+\frac{C_{\mathrm{PC}}}{\left(1+K_{\mathrm{A}_{1} \mathrm{Na}} a_{\mathrm{Na}^{+}}\right)}\right] \frac{1}{a_{\mathrm{H}^{+}}} \\
& +\left[\frac{C_{\mathrm{PC}}}{K_{\mathrm{B}_{1} \mathrm{OH}} K_{w}}+\frac{C_{\mathrm{PG}} K_{\mathrm{A}_{2} \mathrm{H}}}{\left(1+K_{\mathrm{A}_{2} \mathrm{Na}} a_{\mathrm{Na}^{+}}\right)^{2}}\right. \\
& \left.+\frac{C_{\mathrm{PC}} K_{\mathrm{A}_{1} \mathrm{H}}}{\left(1+K_{\mathrm{A}_{1} \mathrm{Na}} a_{\mathrm{Na}^{+}}\right)^{2}}\right] \text {. }
\end{aligned}
$$

The coefficients describing these linear functions can be easily obtained using linear regression and subsequently applied to calculate the parameters. Knowledge of the association constants $K_{\mathrm{A}_{1} \mathrm{H}}, K_{\mathrm{B}_{1} \mathrm{OH}}, K_{\mathrm{A}_{1} \mathrm{Na}}, K_{\mathrm{B}_{1} \mathrm{Cl}}$ is useful in determining the association constants $K_{\mathrm{A}_{2} \mathrm{H}}$, and $K_{\mathrm{A}_{2} \mathrm{Na}}$. Defining the value of these parameters permits the calculation of the theoretical PC-PG membrane surface charge from eq. (19) for comparison to experimental data.

A degree of the coverage of the liposomal surface occupied by $\mathrm{PG}$ with the $\mathrm{H}^{+}, \mathrm{Na}^{+}$ions was determined from the equation

$$
\theta_{x}=\frac{a_{x}}{c_{\mathrm{PG}}}
$$

where $x=\mathrm{A}_{2}^{-}, \mathrm{A}_{2} \mathrm{H}, \mathrm{A}_{2} \mathrm{Na}$.

The degree of the coverage of the PC membrane surface with $\mathrm{H}^{+}, \mathrm{OH}^{-}, \mathrm{Na}^{+}, \mathrm{Cl}^{-}$ions was determined previously [23].

\section{Results and discussion}

The surface charge density values of the PC-PG membrane were determined by microelectrophoresis. Electrophoretic mobility measurements were performed from $p \mathrm{H} 2$ to 10.5 , using $0.9 \% \mathrm{NaCl}$ as a supporting electrolyte. The membrane surface charge densities were calculated by eq. (1). The theoretical values of membrane surface charge density were determined by using the sixequilibrium mathematical model described in the Theory section.

Experimental membrane surface charge densities of pure PC and PC-PG liposomal membranes were plotted as a function of $\mathrm{H}^{+}$ion concentration in the solution and the molar composition of lipids in the membrane (fig. 1). The isoelectric point of the membrane showed a shift towards lower $p \mathrm{H}$ values with increasing $\mathrm{PG}$ content in the membrane, from $p \mathrm{H} \sim 4$ for the $\mathrm{PC}$ membrane, to $p \mathrm{H}$ $\sim 2.5$ for a 10:1 PC: PG membrane. The presence of an anionic lipid (PG) in the PC membrane increased the proportion of negative membrane surface charge density values between $p \mathrm{H} 4$ and 10.5. For $p \mathrm{H}$ values below 4 , the 


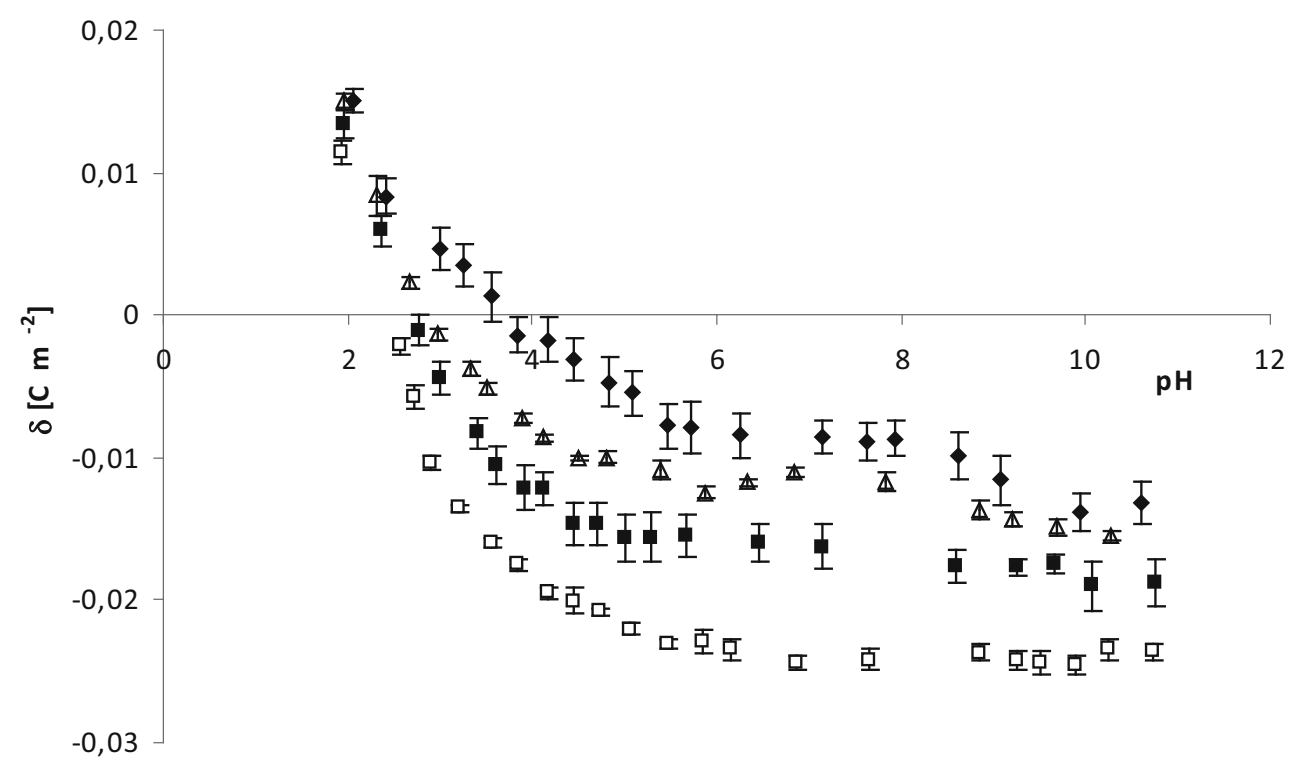

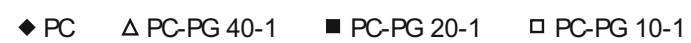

Fig. 1. Experimental membrane surface charge densities for pure PC and PC:PG liposomal membranes as a function of the $p \mathrm{H}$ of the electrolyte solution.

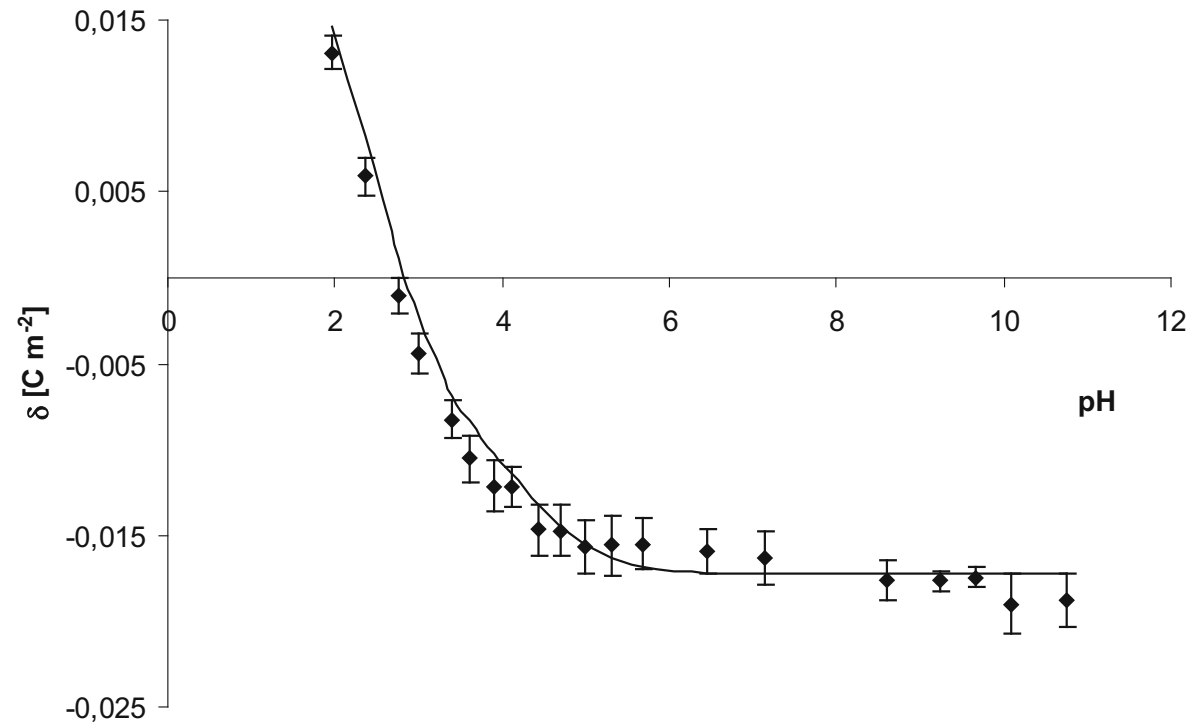

Fig. 2. Membrane surface charge density of the PC:PG liposomal membrane (at a molar ratio of 20:1) as a function of the $p H$ of the electrolyte solution. Points denote experimental values. Continuous line links the theoretical values.

membrane electric charge decreased and showed a change in sign from positive to negative.

We previously determined the association constants between PC surface groups and solution ions, as follows (in $\left.\mathrm{m}^{3} \mathrm{~mol}^{-1}\right): K_{\mathrm{A}_{1} \mathrm{H}}=7.172 \times 10^{2}, K_{\mathrm{A}_{1} \mathrm{Na}}=0.230$, $K_{\mathrm{B}_{1} \mathrm{OH}}=3.351 \times 10^{9}$, and $K_{\mathrm{B}_{1} \mathrm{Cl}}=0.076$ [23]. Here, we used the experimental membrane surface charge densities with these constants to define the association constants of the phosphate group of $\mathrm{PG}$ with the $\mathrm{H}^{+}$and $\mathrm{Na}^{+}$ions. The resulting values were $K_{\mathrm{A}_{2} \mathrm{H}}=0.389$ and $K_{\mathrm{A}_{2} \mathrm{Na}}=1.238 \times 10^{-3} \mathrm{~m}^{3} \mathrm{~mol}^{-1}$, respectively. For these calculations, it was necessary to know the surface concen- trations of $\mathrm{PC}$ and $\mathrm{PG}$. The surface concentration of $\mathrm{PC}$ was determined previously [23], by assuming that the surface area occupied by a single PC molecule was $70 \AA^{2}$ per molecule [27]. The surface concentration of PG was determined by assuming the same surface area occupied by a single PG molecule [27]. Theoretical values of membrane surface charge density were determined by using eq. (19).

Figure 2 shows the membrane surface charge densities of the PC: PG liposomal membrane at a molar ratio of 20:1 plotted as a function of $p \mathrm{H}$. Points denote experimental values, and continuous lines represent the theoretical values obtained from eq. (19). Although their experimental 


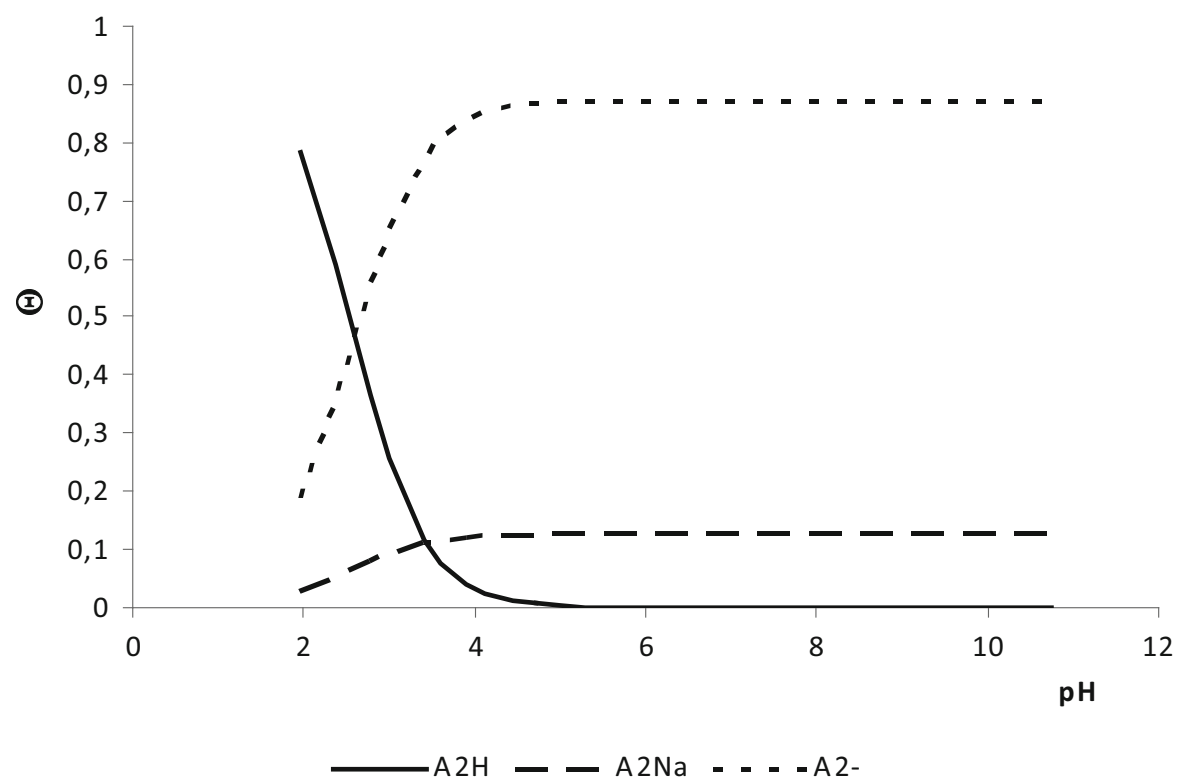

Fig. 3. Degree of coverage of the PG membrane $(\theta)$ with the $\mathrm{H}^{+}$and $\mathrm{Na}^{+}$ions, as a function of $p \mathrm{H}$ of $0.9 \% \mathrm{NaCl}$ solution.

and theoretical data were not included in fig. 2 (due to lack of legibility), good fits were obtained between the experimental and theoretical data points for PC: PG liposomal membranes at molar ratios of 40:1 and 10:1, as in fig. 2. Agreement between the experimental and theoretical points across the whole $p \mathrm{H}$ range proves that our six-equilibrium model proposed to description of the studied PC-PG system is correct.

Figure 3 demonstrates the degree of coverage of the PG membrane surface by solution ions as a function of $p \mathrm{H}$. Coverage of the $\mathrm{PC}$ membrane surface was presented previously [23]. The interaction of $\mathrm{Na}^{+}$ions with the $\mathrm{PG}$ membrane surface had a significant influence on the membrane electric charge. In a strongly acidic solution, the $\mathrm{PO}^{(-)}$groups of $\mathrm{PG}$ were covered by $\mathrm{H}^{+}$ions. When the number of $\mathrm{H}^{+}$ions began to decrease (at $p \mathrm{H}>2$ ), $\mathrm{Na}^{+}$ ions began to associate with the PG surface. Coverage of the $-\mathrm{PO}^{(-)}$groups by $\mathrm{Na}^{+}$ions remained unchanged $(\sim 0.12)$ for $p \mathrm{H}$ values above 4 . Thus, the PG surface was covered to a slight degree, and many free $-\mathrm{PO}^{(-)}$groups remained. The number of free $-\mathrm{N}^{(+)} \mathrm{H}_{3}$ groups also remained unchanged for $p \mathrm{H}$ values above 4 , with a degree of coverage of approximately 0.88 . In comparison, the PC surface coverage by free $-\mathrm{PO}^{(-)}$groups was approximately 0.02 [23]. The surface distribution is reflected in the association constants of the $\mathrm{PC}$ and $\mathrm{PG}$ phosphate groups with $\mathrm{Na}^{+}$ions $\left(0.230\right.$ and $1.238 \times 10^{-3} \mathrm{~m}^{3} \mathrm{~mol}^{-1}$, respectively). This finding implies a higher acidity of the $\mathrm{PG}$ phosphate groups compared to the PC phosphate groups.

\section{Conclusions}

In this paper, we have presented the influence of the $p \mathrm{H}$ and the membrane lipid composition on the membrane surface charge. Membrane surface charge density values of PC:PG liposomal membranes were obtained by microelectrophoresis. The interaction between two-component lipid membranes and solution ions has been well characterized. We developed a six-equilibrium mathematical model of interactions between monovalent ions and the PC-PG liposomal surface, and verified the model experimentally. We determined association constants between the $\mathrm{PG}$ membrane phosphate groups and $\mathrm{H}^{+}$and $\mathrm{Na}^{+}$ ions. By setting the values of these parameters, we were able to calculate model curves, which we compared to the experimental data to verify our model. To our knowledge, the values of the association constants between $\mathrm{Na}^{+}$and $\mathrm{H}^{+}$ions and the phosphate group of PG have heretofore not been obtained.

Open Access This is an open access article distributed under the terms of the Creative Commons Attribution License (http://creativecommons.org/licenses/by/4.0), which permits unrestricted use, distribution, and reproduction in any medium, provided the original work is properly cited.

\section{References}

1. S.A. Tatulian, Biochim. Biophys. Acta 736, 189 (1983).

2. M.A. Akeson et al., Biochim. Biophys. Acta 986, 33 (1989).

3. A. Nelson, J. Chem. Soc. Faraday Trans. 89, 3081 (1993).

4. P. Garidel et al., Biochim. Biophys. Acta 1466, 245 (2000).

5. R.A. Böckmann et al., Biophys. J. 85, 1647 (2003).

6. A.A. Gurtovenko et al., J. Phys. Chem. B. 109, 21126 (2005).

7. B. Klasczyk et al., Langmuir 26(24), 18951 (2010).

8. M. Roux, M. Bloom, Biochemistry 29, 7077 (1990).

9. H. Binder, O. Zschornig, Chem. Phys. Lipids 115, 39 (2002). 
10. A.D. Petelska, Z.A. Figaszewski, J. Membr. Biol. 246, 467 (2013).

11. A.D. Petelska, Z.A. Figaszewski, Cent. Eur. J. Chem. 11, 424 (2013).

12. M. Sovago et al., J. Am. Chem. Soc. 129, 11079 (2007).

13. S.A. Tatulian, Eur. J. Biochem. 170, 413 (1987).

14. C.G. Sinn et al., Colloids Surf. A: Physicochem. Eng. Aspects 282, 410 (2006).

15. X.L. Raffo Iraolagoitia, M.F. Martini, Colloids Surf. B: Biointerfaces 76, 215 (2010).

16. S.A. Pandit et al., Biophys. J. 84, 3743 (2003).

17. R. Vácha et al., J. Phys. Chem. A 113, 7235 (2009).

18. S.R. Deshiikan, K.D. Papadopoulos, Colloid Polym. Sci. 276, 117 (1998).
19. J. Sabin et al., Langmuir 21, 10968 (2005).

20. J.F. Mead, R.B. Alfin-Slater, D.R. Howton, G. Popják, Lipids - Chemistry, Biochemistry and Nutrition (Plenum Press, New York, 1986).

21. S. Uran et al., J. Chrom. B 758, 265 (2001).

22. P. Wydro, K. Witkowska, Colloids Surf. B. 72, 32 (2009).

23. I. Dobrzyńska et al., Chem. Anal. 52, 931 (2007).

24. A.E. Alexander, P. Johnson, Colloid Science (Clarendon Press, Oxford, 1949).

25. G.M. Barrow, Physical Chemistry (McGraw-Hill Inc., New York, 1996).

26. J. Kotyńska et al., J. Bioenerg. Biomembr. 40, 637 (2008).

27. K. Dołowy, A. Szewczyk, S. Pikuła, Biological Membranes (Science Publishing "Silesia", Katowice-Warsaw, 2003). 